\title{
Occurrence of Cerebrovascular Diseases Decreased after the Great East Japan Earthquake and Tsunami of 2011
}

\author{
Shinichi Omama ${ }^{a}$ Nobukazu Komoribayashi ${ }^{a}$ Yoshihiro Inoue $^{b}$ \\ Tomohiko Mase $^{c}$ Kuniaki Ogasawarad Yasuhiro Ishibashi ${ }^{\mathrm{e}}$ \\ Masaki Ohsawa $^{\text {f }}$ Toshiyuki Onodag Kazuyoshi Itai $^{\text {h }}$ Kozo Tanno ${ }^{i}$ \\ Kiyomi Sakatai \\ a Iwate Prefectural Advanced Critical Care and Emergency Center, Iwate Medical University, \\ Yahaba, Japan; ${ }^{\mathrm{b}}$ Division of Critical Care Medicine, Department of Critical Care, Disaster, and \\ General Medicine, Iwate Medical University, Yahaba, Japan; ' ${ }^{\mathrm{D}}$ ivision of Disaster Medicine, \\ Department of Critical Care, Disaster, and General Medicine, Iwate Medical University, \\ Yahaba, Japan; ${ }^{\mathrm{d}}$ Department of Neurosurgery, Iwate Medical University, Yahaba, Japan; \\ e Department of Neurology, Kitakami Saiseikai Hospital, Kitakami, Japan; ${ }^{f}$ Department of \\ Internal Medicine, Morioka Tsunagi Onsen Hospital, Morioka, Japan; ${ }^{9}$ Health Care Center, \\ Iwate University, Morioka, Japan; h Department of Nutritional Sciences, Morioka University, \\ Takizawa, Japan; 'Department of Hygiene and Preventive Medicine, Iwate Medical \\ University, Yahaba, Japan
}

\section{Keywords}

Cerebrovascular disease $\cdot$ Incidence $\cdot$ Stroke register $\cdot$ Tsunami

\begin{abstract}
Background: A temporary increase in the occurrence of cerebrovascular diseases (CVDs) after the Great East Japan Earthquake and Tsunami of 2011 was reported; however, no studies have been conducted to investigate long-term effects. We assessed the long-term impact of the disaster on the incidence of CVDs. Methods: Incidence data for CVDs from 2008 to 2017 were acquired from the population-based Stroke Registry with an inventory survey of Iwate Prefecture, Japan. Part of the coastal area in Iwate Prefecture was mildly flooded and the other part was severely flooded. Age-adjusted incidence rates of CVDs (according to the Japanese standard population) were calculated for each area. The relative risk (RR) of incidence based on the years before the disaster (2008-2010), adjusted by stratified age groups, was calculated for the year of the disaster (2011), and the years after the disaster (2012-2017) in each area. Results: The age-adjusted incidence rates gradually decreased in all areas, with the exception of a temporary increase among men who lived on the coast the year the disaster oc-
\end{abstract}


curred. The adjusted RR in the disaster year were not significant in any area and those of the postdisaster years were $0.91(95 \% \mathrm{Cl} 0.87-0.96)$ for all inland men, $0.93(0.89-0.97)$ for all inland women, $0.85(0.78-0.93)$ for all coastal men, $0.87(0.81-0.94)$ for all coastal women, 0.88 $(0.80-0.98)$ for men at mildly flooded coast, $0.82(0.75-0.89)$ for women at mildly flooded coast, $0.79(0.68-0.91)$ for men at severely flooded coast, and $0.98(0.86-1.11)$ for women at severely flooded coast. Conclusions: The occurrence of CVDs in the flooded coastal areas did not increase in the year of the Great East Japan Earthquake and Tsunami; furthermore, it decreased for men according to the severity of flood damage in the subsequent years; this can be attributed to supportive activities for the tsunami victims and the migration of the population.

(C) 2020 The Author(s)

Published by S. Karger AG, Basel

\section{Introduction}

The giant tsunami waves of the Great East Japan Earthquake and Tsunami of 2011 devastated the Pacific coast of northeastern Japan $[1,2]$. In the aftermath, many tsunami victims who had escaped to evacuation shelters suffered from the loss of their homes and a lack of water, food, and other necessities for living [3]. Most of the victims were moved to provisional housing several months after the disaster [4], and an increase in the occurrence of cerebrovascular diseases (CVDs) soon after the disaster was reported [5, 6]. Victims in the tsunamidevastated area continued to live in provisional housing for several years, until the reconstruction of homes and urban environments had been accomplished [7]. Prolonged unusual living in evacuation shelters and provisional housing following the disaster may have had unfavorable effects on the health of victims [8-10]. However, the long-term impact of the disaster on CVDs has not ever been reported. Japan is an earthquake-prone country, with damage from major earthquakes and huge tsunamis predicted to occur in the near future [11, 12]. Japan is also a country that has one of the highest incidences of CVDs in the world [13]. Thus, revealing the long-term impact a huge tsunami disaster may have on the incidence of CVDs is important.

The aim of this study was to assess the long-term impact of the Great East Japan Earthquake and Tsunami of 2011 on the incidence of CVDs.

\section{Methods}

\section{Iwate Prefecture and Stroke Registry}

Iwate Prefecture is located in the northern part of the main island of Japan and faces the Pacific Ocean. In the coastal municipalities of this prefecture, many buildings were destroyed by the giant tsunami waves of the Great East Japan Earthquake and Tsunami of 2011, but the earthquake caused less damage in the inland municipalities and in coastal areas that did not suffer from flood damage (Fig. 1).

The Iwate Stroke Registry has been in operation since 1991 and is overseen by the government of Iwate Prefecture and the Iwate Medical Association. The inventory survey of the registry has been conducted since 2008 for all hospitals with beds for general patients in Iwate Prefecture and core hospitals in the neighboring areas, except for 3 hospitals that were destroyed due to the huge tsunami of the Great East Japan Earthquake that could only start the survey after they reopened. The diagnostic criteria used for the registry were based on the criteria established for the monitoring system for CVDs commissioned by the Ministry of Health and Welfare, and which correspond to those published by the World Health Organi-

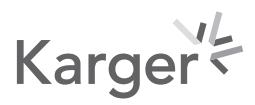




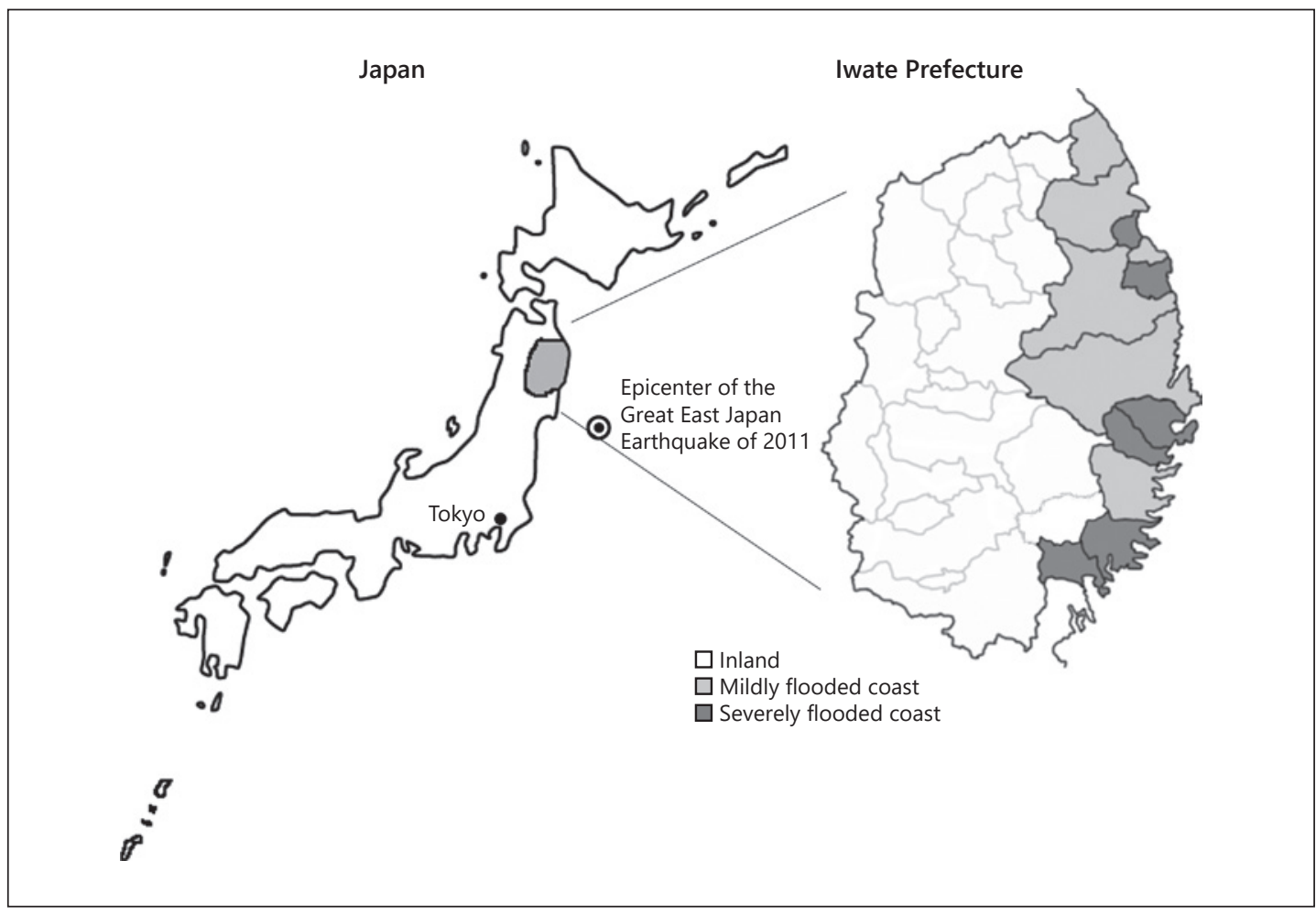

Fig. 1. Map of the study area depicting the municipalities inland and those on the coast that were mildly flooded and severely flooded. The epicenter of the Great East Japan Earthquake of 2011 is shown by a dot with a concentric circle.

zation. Stroke is defined as the sudden onset of neurologic symptoms [14,15]. Details of the Iwate Stroke Registry and its inventory survey have been published elsewhere [16].

\section{Statistical Analyses}

Incidence data on CVDs from 2008 to 2017 were acquired from the Iwate Stroke Registry database. Population data on October 1st each year were acquired from the national census and the demographic forecast produced by the government of Iwate Prefecture. The 12 municipalities of the coastal area were divided into 2 groups based on their flood damage: 6 were categorized as mildly flooded coast with $<40 \%$ of the population living in flooded areas, and 6 municipalities were categorized as severely flooded coast with $\geq 40 \%$ of the population living in flooded areas [17]. The 3 hospitals destroyed by the tsunami disaster were located on the severely flooded coast. The age-adjusted incidence rates of stroke subtypes (all CVDs, cerebral infarction, intracerebral hemorrhage, and subarachnoid hemorrhage) were calculated according to the Japanese standard population in 1985 for each area: all inland, all coast, mildly flooded coast, and severely flooded coast.

To evaluate the impact of the disaster on the incidence of CVDs, age-specific incidence rates by 3 age groups $(35-54,55-74$, and $\geq 75$ years) were calculated for the years before the disaster, i.e., 2008-2010, the disaster year itself, i.e., 2011, and the years after the disaster, i.e., 2012-2017. The age-specific relative risk (RR) of CVD incidence based on the predisaster years by 3 age groups, and the adjusted RR of CVD incidence based on the predisaster years, adjusted by stratified 3 age groups, were calculated for the disaster year and the postdisaster years in each area. 


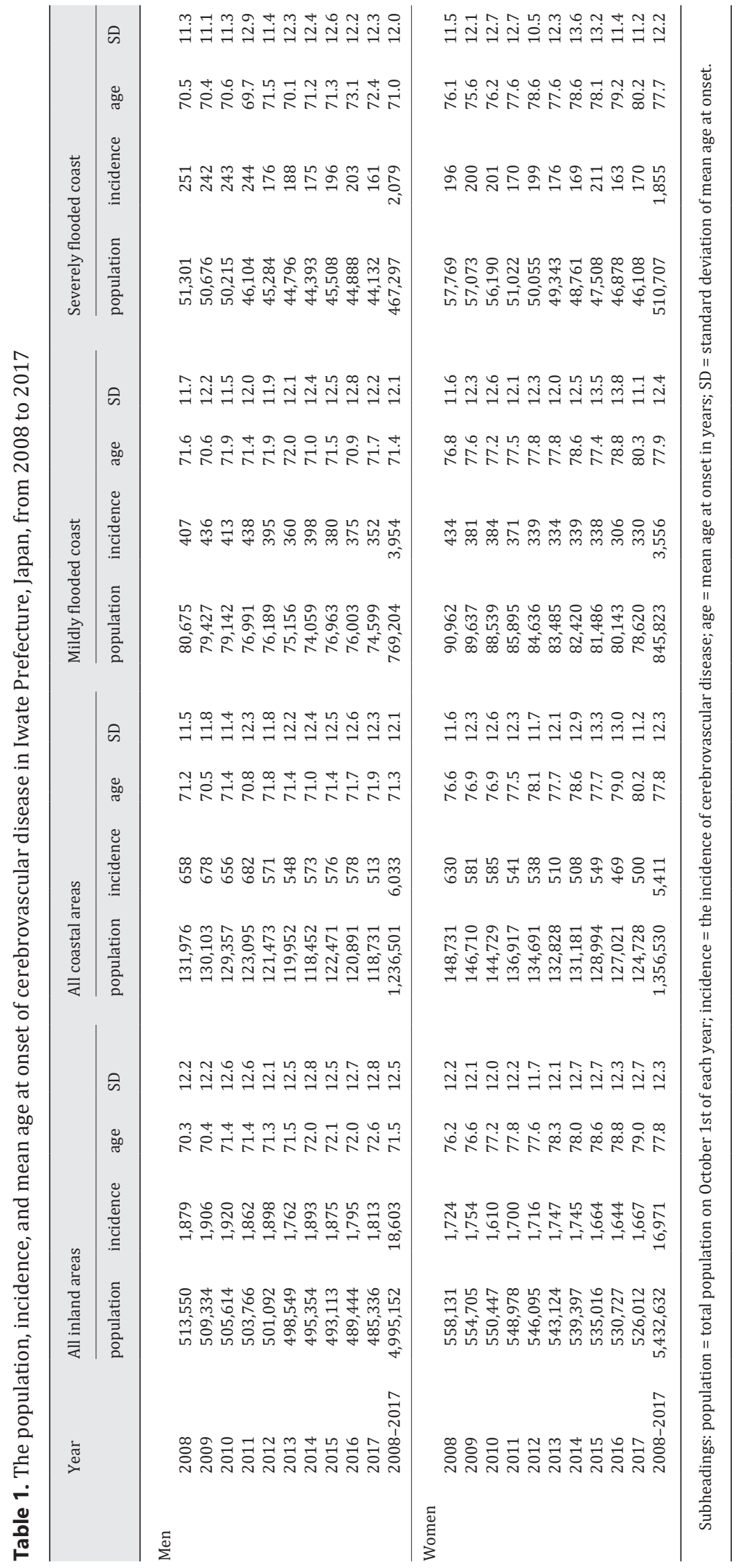

\section{Karger'}


Cerebrovascular Diseases Extra

\begin{tabular}{l|l}
\hline Cerebrovasc Dis Extra 2020;10:105-115 \\
\hline DOI: 10.1159/000509869 & $\begin{array}{l}\text { ○ 2020 The Author(s). Published by S. Karger AG, Basel } \\
\text { www.karger.com/cee }\end{array}$ \\
\hline
\end{tabular}

Omama et al.: Reduced Stroke Occurrence after the Japan Earthquake

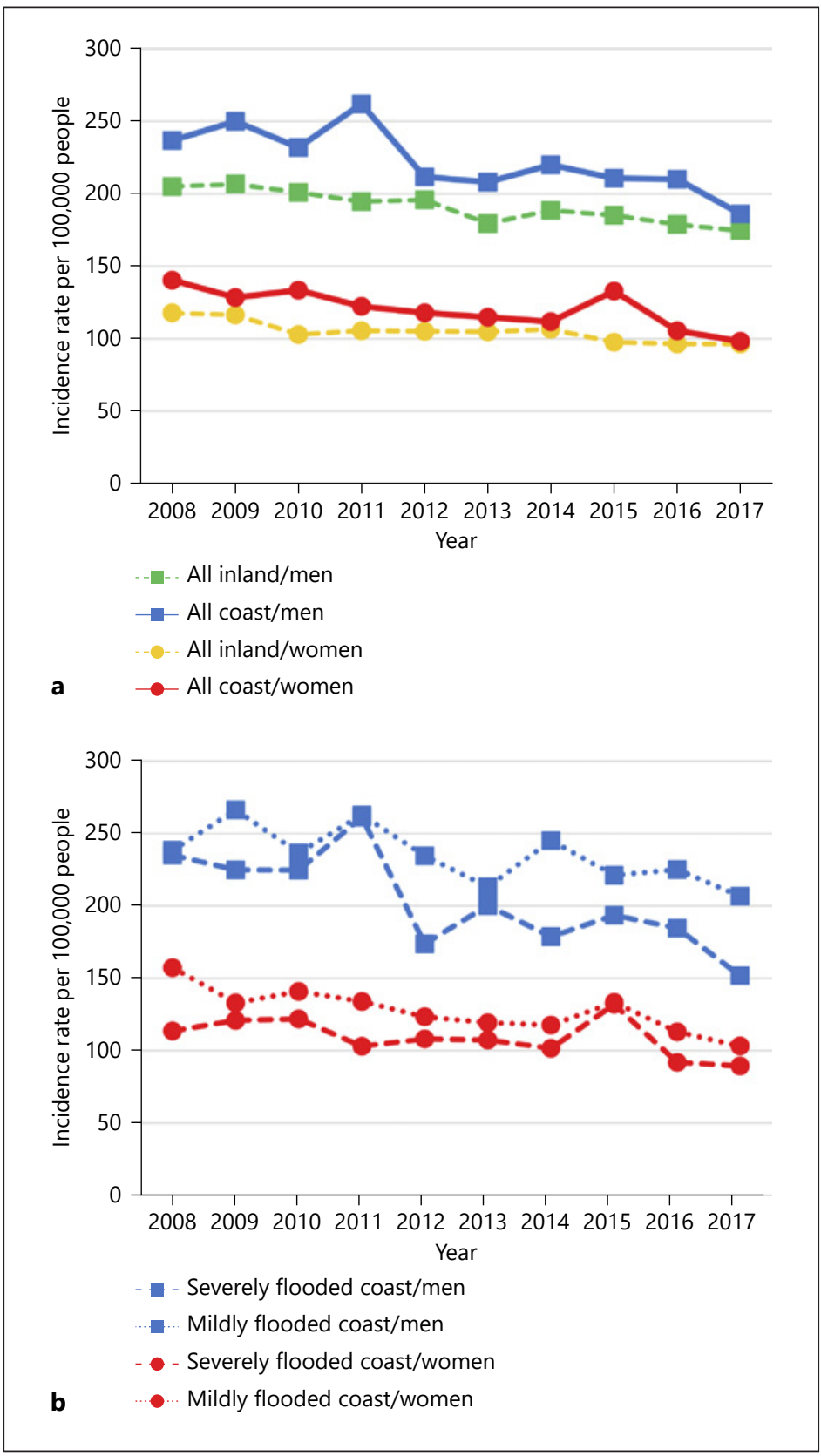

Fig. 2. The graphs show the ageadjusted incidence rate of cerebrovascular diseases from 2008 to 2017 in Iwate Prefecture, Japan. a Comparison of incidence in all inland and all coastal areas. b Comparison of CVD incidence in men and women at the mildly flooded coast and severely flooded coast. 


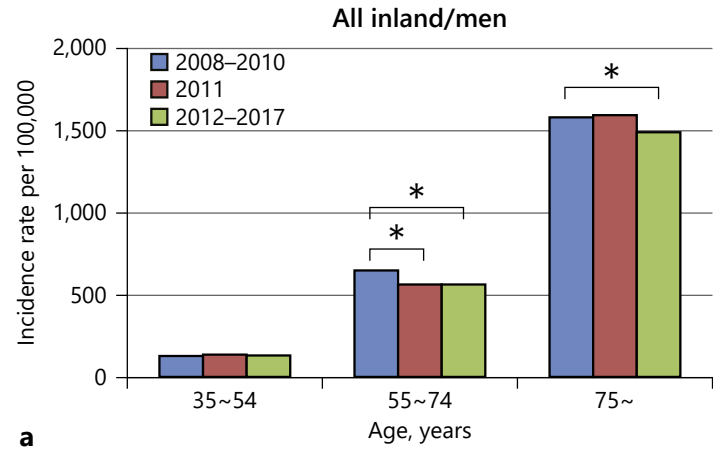

All coast/men

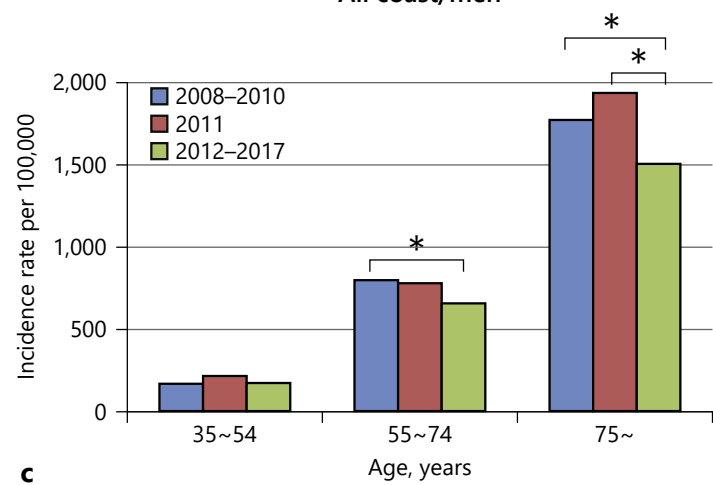

c

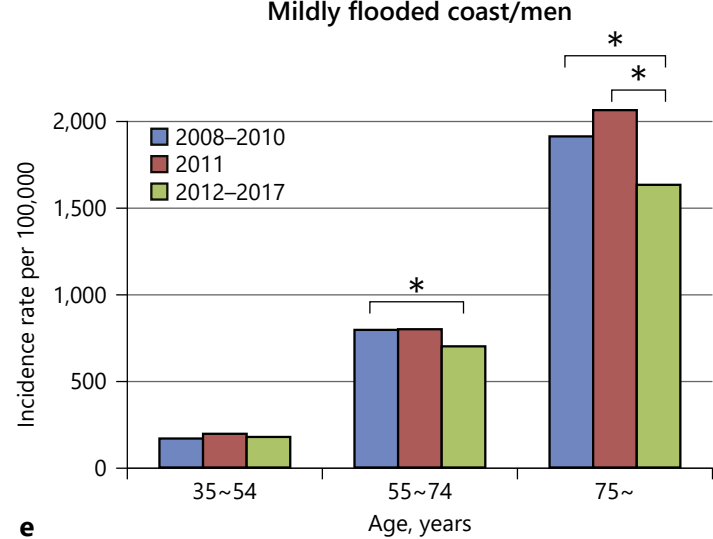

Severely flooded coast/men

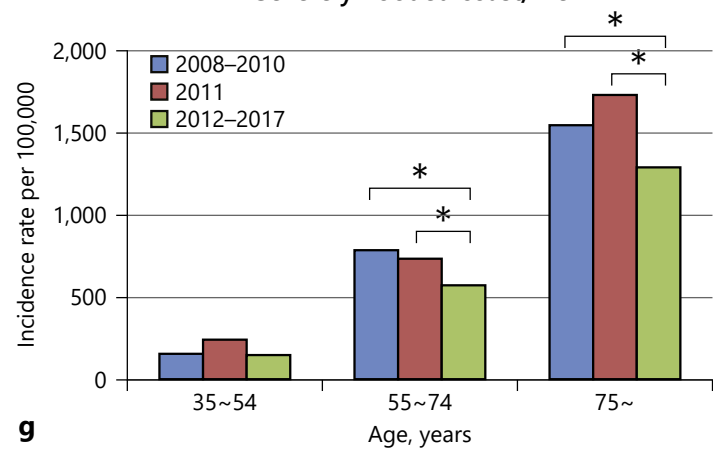

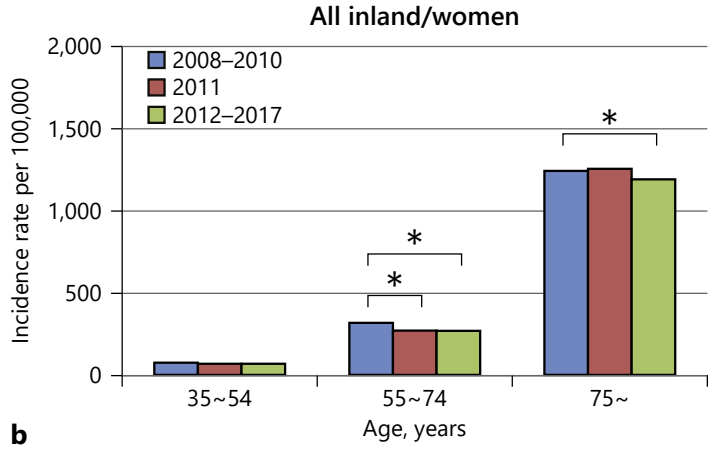

All coast/women

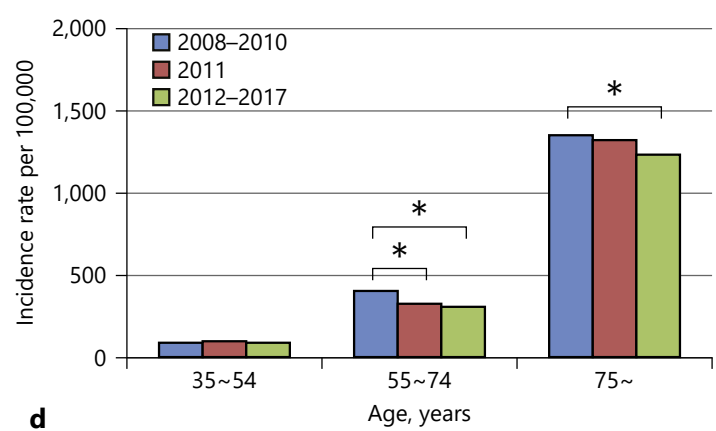

Mildly flooded coast/men

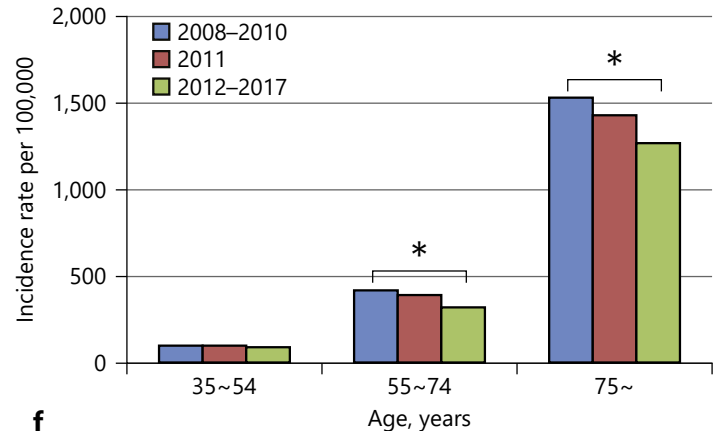

Severely flooded coast/women

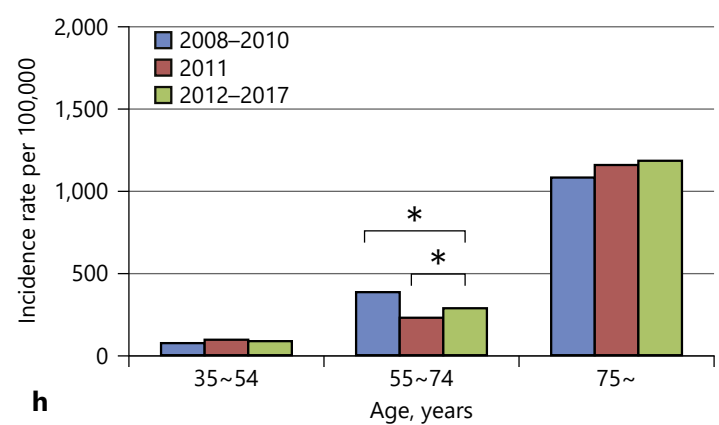

Fig. 3. $\mathbf{a}-\mathbf{h}$ The graphs show the age-specific incidence rate of cerebrovascular diseases in the predisaster years 2008-2010, the disaster year of 2011, and the postdisaster years 2012-2017 in Iwate Prefecture, Japan. $* p<0.05$ indicates statistical significance. 


\section{Cerebrovascular Diseases Extra}

Omama et al.: Reduced Stroke Occurrence after the Japan Earthquake

Table 2. Relative risk of the incidence of cerebrovascular diseases based on the predisaster period, 2008-2010

\begin{tabular}{|c|c|c|c|c|c|c|c|c|c|c|}
\hline & \multirow[t]{2}{*}{ Year(s) } & \multirow[t]{2}{*}{ Age, years } & \multicolumn{2}{|c|}{ All inland areas } & \multicolumn{2}{|c|}{ All coastal areas } & \multicolumn{2}{|c|}{ Mildly flooded coast } & \multicolumn{2}{|c|}{ Severely flooded coast } \\
\hline & & & $\mathrm{RR}$ & $95 \% \mathrm{CI}$ & $\mathrm{RR}$ & $95 \% \mathrm{CI}$ & $\mathrm{RR}$ & $95 \% \mathrm{CI}$ & $\mathrm{RR}$ & $95 \% \mathrm{CI}$ \\
\hline \multicolumn{11}{|l|}{ Men } \\
\hline & 2011 & $35-54$ & 1.06 & $0.90-1.25$ & 1.30 & $0.98-1.72$ & 1.16 & $0.80-1.67$ & 1.54 & $0.99-2.40$ \\
\hline & & $55-74$ & $0.88^{*}$ & $0.81-0.95$ & 0.98 & $0.86-1.11$ & 1.00 & $0.85-1.18$ & 0.93 & $0.75-1.16$ \\
\hline & & $75+$ & 1.00 & $0.93-1.08$ & 1.09 & $0.96-1.25$ & 1.08 & $0.92-1.27$ & 1.11 & $0.89-1.39$ \\
\hline & & adjusted $^{\mathrm{a}}$ & 0.95 & $0.88-1.03$ & 1.06 & $0.93-1.21$ & 1.05 & $0.90-1.23$ & 1.06 & $0.85-1.33$ \\
\hline & 2012-2017 & $35-54$ & 0.99 & $0.89-1.10$ & 1.02 & $0.85-1.23$ & 1.06 & $0.84-1.34$ & 0.95 & $0.69-1.30$ \\
\hline & & $55-74$ & $0.87^{*}$ & $0.83-0.92$ & $0.82 *$ & $0.76-0.89$ & $0.88^{*}$ & $0.80-0.98$ & $0.73^{*}$ & $0.64-0.83$ \\
\hline & & $75+$ & $0.94^{*}$ & $0.90-0.98$ & $0.85^{*}$ & $0.78-0.92$ & $0.85^{*}$ & $0.77-0.94$ & $0.83^{*}$ & $0.72-0.96$ \\
\hline & & adjusted $^{\mathrm{a}}$ & $0.91^{*}$ & $0.87-0.96$ & $0.85^{*}$ & $0.78-0.93$ & $0.88^{*}$ & $0.80-0.98$ & $0.79 *$ & $0.68-0.91$ \\
\hline \multicolumn{11}{|l|}{ Women } \\
\hline & 2011 & $35-54$ & 0.96 & $0.75-1.12$ & 1.06 & $0.70-1.60$ & 0.96 & $0.58-1.61$ & 1.26 & $0.63-2.52$ \\
\hline & & $55-74$ & $0.86^{*}$ & $0.77-0.96$ & $0.81^{*}$ & $0.68-0.98$ & 0.94 & $0.75-1.17$ & $0.59 *$ & $0.42-0.84$ \\
\hline & & $75+$ & 1.01 & $0.95-1.08$ & 0.98 & $0.87-1.10$ & 0.93 & $0.81-1.07$ & 1.07 & $0.87-1.32$ \\
\hline & & adjusted $^{\mathrm{a}}$ & 0.97 & $0.91-1.03$ & 0.93 & $0.83-1.05$ & 0.93 & $0.81-1.08$ & 0.94 & $0.77-1.16$ \\
\hline & $2012-2017$ & $35-54$ & 0.94 & $0.82-1.09$ & 0.98 & $0.76-1.27$ & 0.91 & $0.66-1.25$ & 1.13 & $0.72-1.77$ \\
\hline & & $55-74$ & $0.85^{*}$ & $0.80-0.91$ & $0.76^{*}$ & $0.68-0.85$ & $0.77^{*}$ & $0.67-0.88$ & 0.75 & $0.87-1.32$ \\
\hline & & $75+$ & $0.96^{*}$ & $0.92-0.99$ & $0.91^{*}$ & $0.85-0.98$ & $0.83^{*}$ & $0.76-0.90$ & 1.10 & $0.97-1.24$ \\
\hline & & adjusted $^{\mathrm{a}}$ & $0.93^{*}$ & $0.89-0.97$ & $0.87^{*}$ & $0.81-0.94$ & $0.82 *$ & $0.75-0.89$ & 0.98 & $0.86-1.11$ \\
\hline
\end{tabular}

$* p<0.05$. RR, relative risk; CI, confidence interval.

${ }^{a}$ Relative risk of incidence adjusted by stratified age groups.

previous year). In the postdisaster years, the decline in the population size recovered to that of the predisaster years for all inland men and women, and all coastal women, but showed a mild decline for coastal men (a decrease of $0.7 \%$ annually at the severely flooded coast and $0.5 \%$ at the mildly flooded coast). CVD incidence showed a downward trend during the study years with the exception of a rapid decline in 2012 among all coastal men.

The age-adjusted incidence rates of CVDs by area from 2008 to 2017 are shown in Figure 2. These gradually decreased, with the exception of a temporary increase for men in all coastal areas in the disaster year (Fig. 2a). In the postdisaster years, a major decrease in CVD incidence was observed among men at the severely flooded coast (Fig. 2b).

The age-specific incidence rates of CVDs, by area, in the predisaster years, the disaster year, and the postdisaster years are shown in Figure 3. In all inland areas, the incidence of CVDs for both men and women aged $\geq 55$ years decreased in the postdisaster years compared with rates in the predisaster years (Fig. 3a, b). In all coastal areas, the rate for men aged $\geq 75$ years increased in the disaster year, and the rates for men and women aged $\geq 55$ years decreased in the postdisaster years (Fig. 3c, d). At the mildly flooded coast, the rate for men aged $\geq 75$ years increased in the disaster year, and the rates in men and women aged $\geq 55$ years decreased in the postdisaster years (Fig. 3e, f). At the severely flooded coast, the rates for men aged $<55$ years and for those aged $\geq 75$ years increased in the disaster year, and the rate for men aged $\geq 55$ years decreased in the postdisaster years but the rates for women hardly changed (Fig. 3g, h).

The age-specific and adjusted RRs in the disaster year and postdisaster years are shown in Table 2. In the disaster year, most of the age-specific RRs for both men and women in all areas were not significant, and the adjusted RRs for both men and women in all inland areas and for women in all coastal areas showed a decreasing trend, but these were not significant. The adjusted RR for men in all coastal areas showed an increasing trend, but this was not significant. In the postdisaster years, most of the age-specific RRs for both men and women 
aged $\geq 55$ years in all areas as well as most of the adjusted RRs for both men and women in all areas showed a significant decrease, except for women at the severely flooded coast who did not show a significant change. A comparison of the diminished adjusted RRs between all inland and coastal areas in the postdisaster years showed that those in the coastal areas were greater than those in inland for both men and women. A comparison of the diminished adjusted RRs between the mildly flooded and severely flooded coast in the postdisaster years showed that those for men at the severely flooded coast were greater than for men at the mildly flooded coast, but that those for women at the mildly flooded coast were greater than for women at the severely flooded coast, i.e., an inverse pattern.

The cases of first-ever CVD onset showed similar results (online suppl. Fig. 1, 2, and Table 1; for all online suppl. material, see www.karger.com/doi/10.1159/000509869). The ageadjusted incidence rate of cerebral infarction varied in a pattern similar to that of all CVDs (online suppl. Fig. 3). The age-adjusted incidence rate of intracerebral hemorrhage did not show a sharp peak in the disaster year for either men or women in any areas (online suppl. Fig. 4). The age-adjusted incidence rate of subarachnoid hemorrhage showed a sharp peak in the disaster year for men in all coastal areas, but did not peak in the disaster year for women in all coastal areas or in both men and women inland (online suppl. Fig. 5).

\section{Discussion}

This study revealed that the incidence of CVDs at the tsunami-flooded coast did not increase in the year of the Great East Japan Earthquake and Tsunami of 2011, and that the incidence for men decreased according to the severity of flood damage in the years following the disaster.

An increase in CVDs for a month and then a subsequent decline in incidence after the disaster was previously reported [6]. The victims of the tsunami disaster suffered from severe stress due to health complaints, severe economic problems, relocations, and the lack of social networks [18]. There were reports of elevated blood pressure among tsunami survivors after the disaster [19-21]. Soon after the disaster, several forms of support were offered to the tsunami victims housed in the evacuation shelters, such as medical support, mental health support, and free medical services to those who had lost their homes and family units that had lost their main income [4]. A few months after the disaster, the number of victims who were relocated to provisional housing reached 43,000 , which accounted for $40 \%$ of the population in the tsunami-flooded area [4]. The reduction in the increase of CVDs in the coastal area in the disaster year could have been the result of the support for the victims.

In the postdisaster years, an increase in the treatment and control of hypertension and a significant association between major housing damage and lower blood pressure of victims were reported [22, 23]. The greater suppression of age-adjusted mortality rates of acute myocardial infarction for coastal men in the postdisaster years according to the severity of the flood damage was also confirmed [24] (online suppl. Fig. 6). Many supportive activities for the victims in provisional housing have been continued, and a free medical service is still in place today. The remarkable decrease in CVDs in the coastal area in the postdisaster years is most likely the result.

Conversely, no suppression of CVDs among women in the severely flooded coast of the postdisaster years was seen. Women at the severely flooded coast had a low incidence of CVDs and a lower risk of developing CVDs. They would not have so affected by the disaster, as was the case for young people. The results of this study suggest that supportive activities following a disaster are most effective for people who are in the high-risk group for developing CVDs, i.e., men and the elderly.

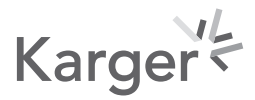


The migration of residents after the disaster was believed to be another factor for the diminished incidence of CVDs in the coastal areas. The decrease in coastal population size according to the severity of flood damage, and the blunting of the decline in the size of the population inland were confirmed, but age-specific differences in these migrations have not been confirmed. No background information about the victims who died or moved away from the coastal areas is available. The elderly or disabled coastal residents at a high risk of developing CVDs were considered dead due to the deterioration of medical and nursing care immediately after the disaster. Survivors with a high risk of developing CVDs were taken to have moved to the inland area in order to have access to medical and nursing care. In the postdisaster years, this migration was set to continue until adequate restoration and reconstruction are achieved. The blunting of the decline in the population of coastal men indicates a migration of many healthy male workers from inland or outside of Iwate prefecture to the coastal areas for the purpose of postdisaster restoration and reconstruction.

Previous studies showing an increase in the incidence of CVDs after the disaster of 2011 were conducted not long after the disaster, i.e., within 1 or 2 years [5, 6]. These studies do not reflect the various forms of support for victims or the migration of the population after the disaster years.

This study had several limitations. The background of registered patients was not evaluated because the Iwate Stroke Registry does not include details such as risk factors for CVDs or residential status following the disaster. The CVD data from before the disaster that was no longer available from the 3 hospitals destroyed at the severely flooded coast could have influenced the incidence of CVDs after the disaster in an incremental manner. A sudden decrease in the population due to death or disappearance in the tsunami disaster and due to relocation after the disaster was not assessed in this study because some municipalities at the severely flooded coast lost their population database for several months due to the damage caused by the tsunami [24]. Several months after the disaster, a rapid decrease in the population of the coastal area gradually recovered to the normal rate of the predisaster years [24]. The CVD incidence rate in the disaster year in the coastal area could have been overestimated, and that of the postdisaster years in the coastal area could have been influenced by the unusual population movement.

The results of this study reflect the conditions that were prevalent in the tsunami-flooded coastal areas for a long time after the disaster. They provide important information about support for the victims, which will be useful after major earthquakes and huge tsunamis that have been predicted to occur in the near future. In the flooded coastal areas, most of the victims of the Great East Japan Earthquake and Tsunami of 2011 will finish relocating from provisional housing to permanent disaster-restoration housing in the near future. Several forms of support, like the free medical service, may be terminated soon. It will be important to continue researching the trends in the occurrence of CVDs in tsunami-flooded coastal areas.

\section{Statement of Ethics}

This study was approved by the Ethics Committees of the Iwate Stroke Registry (approval No. 29-11) and Iwate Medical University, School of Medicine (receipt No. H28-37).

\section{Conflict of Interest Statement}

The authors declare that there are no conflicts of interest.

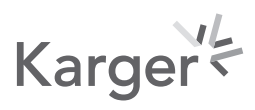




\section{Cerebrovascular Diseases Extra}

\begin{tabular}{l|l}
\hline Cerebrovasc Dis Extra 2020;10:105-115 \\
\hline DOI: 10.1159/000509869 & $\begin{array}{l}\text { @ 2020 The Author(s). Published by S. Karger AG, Basel } \\
\text { www.karger.com/cee }\end{array}$ \\
\hline
\end{tabular}

Omama et al.: Reduced Stroke Occurrence after the Japan Earthquake

\author{
Funding Sources
}

This study was supported by JPSP KAKENHI grant Nos. JP16K09067 and JP19K10627.

\title{
Author Contributions
}

S.O.: concept, design, acquisition, analysis, interpreting, and drafting. N.O., Y. Ishibashi, and M.O.: acquisition, and interpreting. T.M.: concept, and supervision. T.O.: data management, and supervision. K.I. and K.T.: interpreting, and supervision. Y. Inoue, K.O., and K.S.: supervision, and final approval of the manuscript.

\section{References}

1 Japan Meteorological Agency web site. [Internet] The Great East Japan Earthquake [cited April 26, 2020]. Available from: http://www.jma.go.jp/jma/menu/jishin-portal.html. Japanese.

2 The Reconstruction Agency web site. [Internet] Reconstruction and revival situation [cited April 26, 2020]. Available from: http://reconstruction.go.jp/portal/index.html. Japanese.

3 Inoue M, Matsumoto S, Yamaoka K, Muto S. Risk of social isolation among Great East Japan Earthquake survivors living in tsunami-affected Ishinomaki, Japan. Disaster Med Public Health Prep. 2014 Aug;8(4):33340.

4 Iwate Prefecture web site. [Internet] The statement of provisional housing for the Great East Japan Earthquake of 2011 [cited April 26, 2020]. Available from: https://www.pref.iwate.jp/shinsaifukkou/saiken/ sumai/1002513.html. Japanese.

5 Aoki T, Fukumoto Y, Yasuda S, Sakata Y, Ito K, Takahashi J, et al. The Great East Japan Earthquake Disaster and cardiovascular diseases. Eur Heart J. 2012 Nov;33(22):2796-803.

6 Omama S, Yoshida Y, Ogasawara K, Ogawa A, Ishibashi Y, Nakamura M, et al. Influence of the Great East Japan Earthquake and tsunami 2011 on occurrence of cerebrovascular diseases in Iwate, Japan. Stroke. 2013 Jun; 44(6):1518-24.

7 Iwate Prefecture web site. [Internet] The statement of permanent housing for the Great East Japan Earthquake of 2011 [cited April 26, 2020]. Available from: https://www.pref.iwate.jp/kurashikankyou/kenchiku/saigai/ kouei/1010345.html. Japanese.

8 Daito H, Suzuki M, Shiihara J, Kilgore PE, Ohtomo H, Morimoto K, et al. Impact of the Tohoku earthquake and tsunami on pneumonia hospitalisations and mortality among adults in northern Miyagi, Japan: a multicentre observational study. Thorax. 2013 Jun;68(6):544-50.

9 Ueda S, Hanzawa K, Shibata M, Suzuki S. High prevalence of deep vein thrombosis in tsunami-flooded shelters established after the great East-Japan earthquake. Tohoku J Exp Med. 2012 Jul;227(3):199-202.

10 Nakamura M, Tanaka F, Nakajima S, Honma M, Sakai T, Kawakami M, et al. Comparison of the incidence of acute decompensated heart failure before and after the major tsunami in Northeast Japan. Am J Cardiol. 2012 Dec;110(12):1856-60.

11 Japan Meteorological Agency web site. [Internet] The Nankai Trough Earthquake [cited April 26, 2020]. Available from: https://www.data.jma.go.jp/svd/eqev/data/nteq/index.html. Japanese.

12 Anan H, Kondo H, Akasaka O, Oshiro K, Nakamura M, Kiyozumi T, et al. Investigation of Japan Disaster Medical Assistance Team response guidelines assuming catastrophic damage from a Nankai Trough earthquake. Acute Med Surg. 2017 Apr;4(3):300-5.

13 Omama S, Yoshida Y, Ogasawara K, Ogawa A, Ishibashi Y, Ohsawa M, et al. Incidence rate of cerebrovascular diseases in northern Japan determined from the Iwate Stroke Registry with an inventory survey system. J Stroke Cerebrovasc Dis. 2013 Nov;22(8):e317-22.

14 WHO MONICA Project Principal Investigators. The World Health Organization MONICA Project (monitoring trends and determinants in cardiovascular disease): a major international collaboration. J Clin Epidemiol. 1988;41(2):105-14.

15 World Health Organization. International statistical classification of diseases and related health problems. 10th rev. 2nd ed. Geneva: World Health Organization; 2003.

16 Omama S, Ogasawara K, Inoue Y, Ishibashi Y, Ohsawa M, Onoda T, et al. Ten-Year Cerebrovascular Disease Trend Occurrence by Population-based Stroke Registry in an Aging Japan Local Prefecture. J Stroke Cerebrovasc Dis. 2020 Mar;29(3):104580.

17 Statistics Bureau. Ministry of Internal Affairs and Communications web site. [Internet] Overall condition of the flooded areas [cited April 26, 2020]. Available from: http://www.stat.go.jp/info/shinsai/pdf/sinsui03. pdf. Japanese. 


\section{Cerebrovascular Diseases Extra}

\begin{tabular}{l|l}
\hline Cerebrovasc Dis Extra 2020;10:105-115 \\
\hline DOI: 10.1159/000509869 & $\begin{array}{l}\text { @ } 2020 \text { The Author(s). Published by S. Karger AG, Basel } \\
\text { www.karger.com/cee }\end{array}$ \\
\hline
\end{tabular}

Omama et al.: Reduced Stroke Occurrence after the Japan Earthquake

18 Yokoyama Y, Otsuka K, Kawakami N, Kobayashi S, Ogawa A, Tannno K, et al. Mental health and related factors after the Great East Japan earthquake and tsunami. PLoS One. 2014 Jul;9(7):e102497.

19 Murakami H, Akashi H, Noda S, Mizoue T, Okazaki O, Ouchi Y, et al. A cross-sectional survey of blood pressure of a coastal city's resident victims of the 2011 Tohoku tsunami. Am J Hypertens. 2013 Jun;26(6):799-807.

20 Satoh M, Kikuya M, Ohkubo T, Imai Y. Acute and subacute effects of the great East Japan earthquake on home blood pressure values. Hypertension. 2011 Dec;58(6):e193-4.

21 Hoshide S, Nishizawa M, Okawara Y, Harada N, Kunii O, Shimpo M, et al. Salt intake and risk of disaster hypertension among evacuees in a shelter after the Great East Japan Earthquake. Hypertension. 2019 Sep;74(3): 564-71.

22 Nagai M, Ohira T, Takahashi H, Nakano H, Sakai A, Hashimoto S, et al.; Fukushima Health Management Survey. Impact of evacuation on trends in the prevalence, treatment, and control of hypertension before and after a disaster. J Hypertens. 2018 Apr;36(4):924-32.

23 Shiba K, Hikichi H, Aida J, Kondo K, Kawachi I. Long-Term Associations between Disaster Experiences and Cardiometabolic Risk: A Natural Experiment from the 2011 Great East Japan Earthquake and Tsunami. Am J Epidemiol. 2019 Jun;188(6):1109-19.

24 Department of Health and Welfare, Government of Iwate Prefecture. Annual report of statistics of migration in Iwate Prefecture. Morioka: Department of Health and Welfare, Government of Iwate Prefecture; 20082017. Japanese. 